\title{
Association between the UBE2Z rs46522 and TCF7L2 rs7903146 polymorphisms with type 2 diabetes in south western Iran
}

\author{
Ali Mohammad Foroughmand ${ }^{1}$, Sana Shafidelpour ${ }^{1}$, Merhrnoosh Zakerkish ${ }^{2}$, Mehdi Pourmehdi Borujeni ${ }^{3}$
}

1. Department of Genetics, Faculty of Sciences, Shahid Chamran University of Ahvaz, Ahvaz, Iran.

2. Department of Endocrinology and Metabolism, Health Research Institute, Diabetes Research Center, Ahvaz Jundishapur University of Medical Sciences, Ahvaz, Iran.

3. Department of Food Hygiene and Quality control, Faculty of Veterinary Medicine, Shahid Chamran University of Ahvaz, Ahvaz, Iran.

\begin{abstract}
Background: Transcription factor 7-like 2 Protein (TCF7L2) has a strong role in the pathogenesis of type 2 diabetes mellitus (T2DM). Association between rs7903146 and T2D risk reported in some of populations. Also many loci such as UBE2Z rs 46522 are affecting by TCF7L2 transcription factor have been found associated with T2D. The present study aimed to evaluate association of the SNPs with risk of T2D among our population.

Methods: This case-control study was conducted on 150 T2D patients and 150 healthy people (as a control group) in south western Iran. Genotyping was performed by PCR-RFLP.

Results: The frequency of genotypes showed no remarkable difference between T2DM patients and control group. The odds ratios of rs7903146 (C/T) poly $\neg$ morphism for $\mathrm{CC}$ and TC genotypes were 1.9 (95\% CI, 0.85 to 4.24; $\mathrm{P}=0.12)$ and $0.81(95 \%$ $\mathrm{CI}, 0.47$ to $1.38 ; \mathrm{P}=0.43)$ compared with the TT genotype, respectively. The odds ratios of rs $46522(\mathrm{C} / \mathrm{T})$ poly $\neg$ morphism for TT and TC genotypes were 1.75 (95\% CI, 0.86 to 3.59; $\mathrm{P}=0.13$ ) and 1.38 (95\% CI, 0.81 to 2.35 ; $\mathrm{P}=0.24)$ compared with the CC genotype, respectively.
\end{abstract}

Conclusion: Our study indicates no association of T2D in south western Iran with the rs7903146 and rs46522 variants.

Keywords: Transcription Factor 7-Like 2 Protein, Diabetes Mellitus, Polymorphism.

DOI: https://dx.doi.org/10.4314/ahs.v19i3.24

Cite as: Foroughmand AM, Shafidelpour S, Zakerkish M, Borujeni MP. Association between the UBE2Z rs46522 and TCF7L2 rs7903146 polymorphisms with type 2 diabetes in south western Iran. Afri Health Sci. 2019;19(3): 2484-2490. https://dx.doi. org/10.4314/ahs.v19i3.24

\section{Introduction}

Diabetes mellitus type 2 (T2DM) is known as one of the most common metabolic diseases. During the five years (from 2008 to 2012), the diabetes prevalence increased with a growth rate of $22.5 \%$ for the world and $23.4 \%$ for Iran $^{1}$. The prevalence of diabetes in Iran is reported to be 9.9 to $13.6 \%{ }^{2,3}$. Obesity, dietary factors and inactive lifestyle are risk factors for $\mathrm{T} 2 \mathrm{DM}^{4,5}$. Also, genetic fac-

\section{Corresponding author: \\ Mehrnoosh Zakerkish, \\ Health Research Institute, \\ Diabetes Research Center, \\ Ahvaz Jundishapur University \\ of Medical Sciences, Ahvaz, Iran. \\ Email: Zakerkishm@yahoo.com}

tors have a role in the occurrence and development of $\mathrm{T}^{2} \mathrm{DM}^{6,7}$.

The single nucleotide polymorphisms (SNPs) of the transcription factor 7-like 2 gene, on 10q25.3 locus, have showed strong association with T2DM risk in differentpopulations, however most loci have been reported to be associated with small effect sizes ${ }^{8}$. The single nucleotide polymorphisms within the TCF7L2 gene have the strongest effect on $\mathrm{T}_{2} \mathrm{DM}^{9}$. Also, this gene shows association with the risk of gestational diabetes and PTDM (Post transplantation diabetes mellitus) ${ }^{10,11}$. Among the T2DM, the rs7903146(C/T) polymorphism of TCF7L2 gene have shown the most significant associations in nearly all populations and ethnics. However, the frequency of the rs7903146 risk allele is considerably less in Asian studies. Some studies reported no association with T2DM in some Asian ethnic populations ${ }^{12,13}$.

\footnotetext{
African C 2019 Foroughmand et al. Licensee African Health Sciences. This is an Open Access article distributed under the terms of the Creative commons Attribution License (https://creativecommons.org/licenses/BY/4.0), which permits unrestricted use, distribution, and reproduction in any medium, provided the original work is properly cited.
} 
TCF7L2 as a transcription factor affects several intercellular functions. It acts as a member of the Wnt signaling pathway. With ligand banding of Wnt to it's receptor, the Wnt signaling pathway turns on. At the following, $\beta$-catenin interacts with BCL9 and translocate to the nucleus. The association of $\beta$-catenin with TCF7L2 in the nucleus result in the activation of some target genes such as proglucagon gene ${ }^{14}$. TCF7L2 represses the expression of proglucagon gene in endocrine cells ${ }^{15,16}$. Recently, it was clear that disruption of the Wnt signaling pathway could lead to emerging T2DM. Wilfred et al show that the CT/ TT genotypes of SNP rs7903146 are strongly associated with the risk of T2D in two independent cohorts. Their investigations on pancreatic islets cell of T2DM cases show the increase of TCF7L2 mRNA levels. Besides, the study of TCF7L2 expression in pancreatic islets of the $\mathrm{T}$ allele carriers show a considerable increase in mRNA production of TCF7L2, which is associated with abnormal insulin secretion and incretin efficacy ${ }^{17}$.

Until now two incertins have been identified (GIP and GLP-1 $)^{18}$. GLP-1 is the central player in glucose homeostasis and insulin secretion. Thus, it is indicated that TCF7L2 genetic variants increase the risk of T2DM by altering GLP-1 levels ${ }^{19}$ and affecting the beta cell proliferation and apoptosis level. The regulation of TCF7L2, the effects on the protein level and its outcomes are not perfectly understood. More investigations are needed to find out the molecular mechanism which an intronic region in TCF7L2 affects pancreatic islet function ${ }^{20}$.

One of the genes affecting TCF7L2, which its association with T2DM has recently been found, is UBE2Z gene. This gene is located on $17 \mathrm{q} 21.32$ locus and includes 6 exons. It has been shown that UBE2Z has a high expression level in human tissues, especially in the pancreas. It has a major role in the ubiquitin system ${ }^{21}$. Ubiquitination is the process of binding ubiquitin protein to a cellular protein. Ubiquitin conjugating enzyme (E2) has a significant role in the ubiquitination process. Unfortunately not much information was detected about human UBE2Z ${ }^{21}$. However, the polymorphism rs46522 within the second intron of UBE2Z gene already was found to have an association with coronary heart disease and this association has been confirmed by subsequent studies $^{22}$. Recently Johnson et al, by integrating the data from the TCF7L2 genoe-wide occupancy behavior study with cross referencing GWAS-derived statistics with specific data, and analyzing the result, revealed UBE2Z rs46522 as a novel type 2 diabetes locus ${ }^{23}$. To our knowledge no study has yet concerned the association of this SNP with T2DM in a case-control study. The aim of this study was to evaluate the association between the UBE2Z rs46522 and TCF7L2 rs7903146 variants with T2D in a khuzestanian population (south western Iran).

\section{Materials and methods \\ Participants}

Total sample of this case - control study was 300 subjects randomly selected from the Khuzestan provinces situated in the south west of Iran and representative of Arab and non- Arab populations. The T2DM patients group were recognized based on ADA criteria (fasting plasma glucose $\geq 126 \mathrm{mg} / \mathrm{dl}$ and /or $2 \mathrm{~h}$ plasma glucose $\geq 200 \mathrm{mg} /$ dl) and consist of 150 individuals (males/females:73/77). The control group too, consist of 150 individuals (males / females: 77/73) that were not recognized with T2DM according to clinical and laboratory examinations. For both case and control groups, personal data (age, gender, diabetes family history and the degree of obesity using the body mass index (BMI) and clinical data (fasting plasma glucose, triglyceride and total cholesterol) were analyzed. The rationale behind the minimum age selection was to ensure the absence of silent diabetics within the control group.

\section{DNA genotyping}

A $5 \mathrm{~mL}$ blood sample was collected in EDTA containing tubes and stored at $-40^{\circ} \mathrm{C}$ for DNA extraction. Leukocyte genomic DNA was extracted from the blood specimen using salting- out method and was quantified by Nano Drop and agarose electrophoresis in order to being used in the polymerase chain reaction (PCR). Genotyping was done employing PCR-RFLP method. The TCF7L2 rs7903146 polymorphic site (C/T) was amplified by M-PCR (in Miss-match primer PCR; a Miss match base in the third position from $3^{\prime}$ end of forward primer in order to make restriction site for the restriction enzyme RsaI was used) using the primer pair 5' - T'TAGAGAGCTAAGCACT'T'T'TAGG TA - 3' ( Miss-match forward primer) and 5' - AGA GAT GAA ATG TAG CAG TGA AGT $G-3^{\prime}$ (reverse primer). 
PCR was carried out by the use of a thermal cycler. TCF7L2 primers were designed based on previous study ${ }^{24}$. PCR cycling conditions included initial denaturation at $95^{\circ} \mathrm{C}$ for 4 minutes, 35 cycles of denaturation at $95^{\circ} \mathrm{C}$ for 30 seconds, annealing at $58^{\circ} \mathrm{C}$ for 30 seconds, extension at $72^{\circ} \mathrm{C}$ for 45 seconds, and final extension at $72^{\circ} \mathrm{C}$ for 5 minutes. PCR product (201-bp) was verified on $1.5 \%$ agarose gel using safe stain (figure 1.A).

The 201-bp product was digested with $0.8 \mu \mathrm{l}$ of restriction enzyme RsaI for 4 hours at $37^{\circ} \mathrm{C}$ followed by $3 \%$ agarose gel electrophoresis gel. T-allele was not cleaved by RsaI and gave a 201-bp band, and C-allele was cleaved into two bonds 175-bp and 26-bp (figure 1.B).

The rs46522 polymorphism $(\mathrm{C} / \mathrm{T})$ was amplified by the PCR method using the primer pair 5'-GCTCACCTCTCCGATTACAC-3' (forward) and 5'-GGAAGGTTGG-
GAATAGGGC-3’ (reverse). The primers were designed employing Allel ID 6. Oligonucleotide primers were prepared from the Pishgam company for both PCRs. PCR conditions were as follows: initial denaturation at $95^{\circ} \mathrm{C}$ for $7 \mathrm{~min}, 35$ cycles of denaturation at $95^{\circ} \mathrm{C}$ for $30 \mathrm{~s}$, annealing at $57^{\circ} \mathrm{C}$ for $40 \mathrm{~s}$, extension at $72^{\circ} \mathrm{C}$ for $25 \mathrm{~s}$ and final extension at $72^{\circ} \mathrm{C}$ for $10 \mathrm{~min}$. PCR product (342-bp) was verified on $1.5 \%$ agarose gel (figure $1 . C$ ). The PCR product was digested with $0.5 \mu$ l of Restriction enzyme BseGI (BtScI) at $55^{\circ} \mathrm{C}$ for 4 hours followed by $2.5 \%$ agarose gel electrophoresis (figure 1.D). The T-allele was not cleaved by BseGI and gave a 342-bp band and the T-allele was cleaved into two bonds 275- and 67-bp (figure 1.D). Genotyping results were cofirmed by direct sequencing. Statistical analyses were performed bySPSS version 19.

A
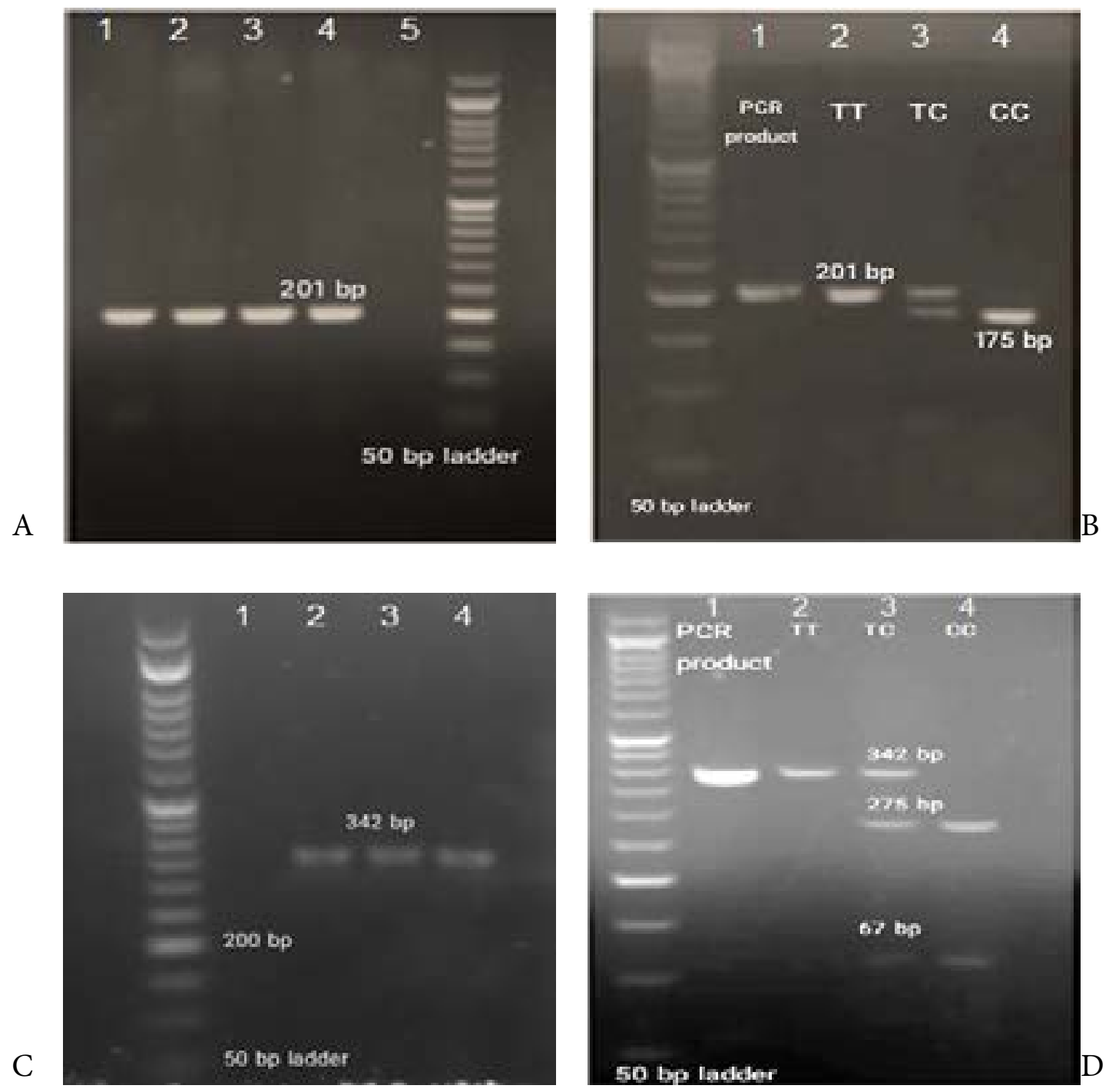

Fig 1. A. 1.5 percent of electrophoresis gel. Lane 1-4 PCR product. Lane 5, negative control of PCR products. B. 3 percent of electrophoresis gel of RFLP product. Lane 1, undigested PCR product. Lane 2-4 RFLP products. C. 1.5 percent of electrophoresis gel. Lane 1, negative control of PCR product. Lane 2-4 PCR products. D. 3 percent of electrophoresis gel of RFLP product. Lane 1, undigested PCR product. Lane 2-4 RFLP products. 


\section{Results}

Comparison between the control and T2DM patients shows no significant differences observed in distribution of number and sex ( $\mathrm{p}>0.05)$. But for age, significant differences between two groups were observed. Control subject were almost older than patients $(56.75 \pm 7.37$ vs. $52.46 \pm 7.37, \mathrm{P}<0.001)$. The result of comparison demo- graphic and biochemical characteristics all subjects are shown in Table 1.

The fasting blood glucose (FBG) and triglyceride (TG) were significantly higher in case group than the healthy individuals $(\mathrm{P}<0.001)$. No significant difference was observed in total cholesterol (TC) between the two groups (Table 1).

\section{Table 1. Clinical data of the study subjects}

\begin{tabular}{|c|c|c|c|}
\hline Variable & Controls & Patients & P value \\
\hline $\begin{array}{c}\text { Sex, } \\
\text { male/female }\end{array}$ & $73 / 77(\% 48.7 / \% 51.3)$ & $77 / 73(\% 51.3 / \% 48.7)$ & 0.74 \\
\hline Age, year & $56.75 \pm 7.37$ & $52.46 \pm 7.37$ & $<0.001$ \\
\hline BMI, kg/m2 & $26.75 \pm 4.25$ & $28.92 \pm 5.03$ & $<0.001$ \\
\hline $\mathrm{FBG}, \mathrm{mg} / \mathrm{dl}$ & $91.29 \pm 6.38$ & $172.2 \pm 81.37$ & $<0.001$ \\
\hline $\mathrm{TC}, \mathrm{mg} / \mathrm{dl}$ & $184.31 \pm 53.51$ & $177.61 \pm 48.48$ & $<0.21$ \\
\hline $\mathrm{TG}, \mathrm{mg} / \mathrm{dl}$ & $124.21 \pm 58.42$ & $145.02 \pm 55.94$ & $<0.001$ \\
\hline
\end{tabular}

For rs7903146, the $\mathrm{T}$ allele frequency of the cases and controls was $54.3(\%)$ and $58.0(\%)(\mathrm{P}=0.37)$ respectively. The frequency of CC, CT and TT genotype were respectively $17.3 \%, 56.7 \%$ and $26.0 \%$ in patients and $8.7 \%$,
$66.7 \%$ and $24.7 \%$ in controls. The rs $7903146(\mathrm{C} / \mathrm{T})$ polymorphism odds ratios for $\mathrm{CC}$ and TC genotypes were 1.9 (95\% CI, 0.85 to $4.24 ; \mathrm{P}=0.12$ ) and 0.81 (95\% CI, 0.47 to 1.38; $\mathrm{P}=0.43)$ compared with the TT genotype, respectively (Table 2).

\section{Table 2: Genotype analysis of patients and controls for rs7903146}

\begin{tabular}{|c|c|c|c|c|}
\hline Genotype/Allele & $\begin{array}{c}\text { Patients } \\
\mathrm{N}(\%)\end{array}$ & $\begin{array}{c}\text { Controls } \\
\mathrm{N}(\%)\end{array}$ & OR(95\%CI) & P-value \\
\hline $\mathrm{CC}$ & $26(17.3)$ & $13(8.7)$ & $1.9(0.85-4.24)$ & 0.12 \\
\hline $\mathrm{CT}$ & $85(56.7)$ & $100(66.7)$ & $0.81(0.47-1.38)$ & 0.43 \\
\hline $\mathrm{TT}$ & $39(26.0)$ & $37(24.7)$ & - & - \\
\hline $\mathrm{CC}+\mathrm{CT}$ & $111(74.0)$ & $113(75.3)$ & $1.09(0.76-1.55)$ & 0.65 \\
\hline $\mathrm{TT}+\mathrm{CT}$ & $124(82.7)$ & $137(91.3)$ & - & - \\
\cline { 1 - 2 } $\mathrm{C}$ & $137(45.7)$ & $126(42.0)$ & $1.16(0.84-1.6)$ & 0.37 \\
\cline { 1 - 2 } $\mathrm{T}$ & $163(54.3)$ & $174(58.0)$ & & \\
\hline
\end{tabular}

For rs 46522 , the $\mathrm{T}$ allele frequency of the cases and controls was $47.6(\%)$ and $41.6(\%)(\mathrm{P}=0.14)$. The frequency of CC, CT and TT genotype were respectively $23.3 \%, 58.0 \%$ and $18.7 \%$ in patients and $30.7 \%, 55.3 \%$ and $14.0 \%$ in controls. The rs $46522(\mathrm{C} / \mathrm{T})$ polymorphism odds ratios for TT and TC genotypes were $1.75(95 \%$ CI, 0.86 to 3.59 ; $\mathrm{P}=0.13$ ) and 1.38 ( $95 \% \mathrm{CI}, 0.81$ to 2.35 ; $\mathrm{P}=0.24)$ compared with the CC genotype, respectively (Table 3). 
Table 3: Genotype analysis of patients and controls for rs 46522

\begin{tabular}{|c|c|c|c|c|}
\hline Genotype/Allele & $\begin{array}{c}\text { Patients } \\
\mathrm{N}(\%)\end{array}$ & $\begin{array}{c}\text { Controls } \\
\mathrm{N}(\%)\end{array}$ & OR(95\%CI) & P-value \\
\hline $\mathrm{CC}$ & $35(23.3)$ & $46(30.7)$ & - & - \\
\hline $\mathrm{CT}$ & $87(58.0)$ & $83(55.3)$ & $1.38(0.81-2.35)$ & 0.24 \\
\hline $\mathrm{TT}$ & $27(18.7)$ & $21(14.0)$ & $1.75(0.86-3.59)$ & 0.13 \\
\hline $\mathrm{CC}+\mathrm{CT}$ & $122(51.5)$ & $129(55.4)$ & - & - \\
\hline $\mathrm{TT}+\mathrm{CT}$ & $115(48.5)$ & $104(44.6)$ & $1.17(0.81-1.68)$ & 0.4 \\
\hline $\mathrm{C}$ & $157(52.3)$ & $175(58.3)$ & $1.28(.92-1.76)$ & 0.14 \\
\hline T & $143(47.6)$ & $125(41.6)$ & & \\
\hline
\end{tabular}

No significant difference in genotype frequencies was observed between T2DM patients and normoglycemic controls. Thus we found no association of rs 46522 with T2DM and also our results on rs7903146 did not confirm the association of this widely replicated Variant of TCF7L2 gene with increased risk of T2DM in Khuzestan province.

Considering the genotypes frequency and statistical computations performed for gene pool of the entire population studied $(300 \mathrm{n})$, not in study of rs46522 (with P-value of0.002) not in rs7903146 study $(\mathrm{P}<0.001)$ The Hardy-Weinberg equilibrium (HWE) is not seen.

\section{Discussion}

Diabetes mellitus is the eighth most frequent leading cause of death throughout the world and its prevalence is increasing worldwide. T2DM is the most frequent $(90 \%)$ type of DM. Multiple genes and environmental factors affect the prevalence of T2DM ${ }^{25}$. The TCF7L2 locus has been shown to have a considerable effect on the pathogenesis of $\mathrm{T}_{2} \mathrm{DM}^{22}$. Among the 8 SNPs located within this gene, the most significant associations have been found between rs7903146 and T2DM risk in almost all groups, expect in some ethnic populations (such as some groups of Arabs) $)^{12,24}$. Association between rs7903146 $(\mathrm{C} / \mathrm{T})$ and $\mathrm{T} 2 \mathrm{DM}$ was already assessed in five studies in different states of Iran. In four of these studies (in Golestan, Ilam, Esfahan and Rafsanjan), the rs 7903146 variant showed a positive significant association with T2DM. However, in another study (in Jahrom, Iran) this polymorphism showed lack of association with $\mathrm{T} 2 \mathrm{DM}^{24-29}$.

One of the genes affecting TCF7L2, whose association with T2DM has been recently found, is the UBE2Z gene. The product of this gene, UBE2Z enzyme has a major role in the ubiquitin system ${ }^{21}$. The polymorphism $\mathrm{rs} 46522$ within the second intron of this gene already was found to have an association with coronary heart disease and the association was confirmed by subsequent studies (22/ a>). Recently Johnson et al reported UBE2Z rs 46522 as a novel T2DM locus ${ }^{23}$. We studied the association of rs46522 with T2DM for the first time in the Khuzestan province and in the world.

Our investigation shows no considerable difference in frequency of genotypes between control and cases groups. Thus we found no association of rs 46522 with T2DM and also our results on rs7903146, did not confirm this variant's association with increased risk of T2DM in Khuzestan province population (including Arab and non-Arab), in contrast with previous reports in other states of Iran and many other part of the world. Differences in ethnic background in the world and within Iran, environmental effect, like life-style, and sample sizesof studies may explain these discrepancies. It is suggested to determine more precisely the effect sizes of both SNPs (rs46522 and rs7903146) in each major ethnic group in each area and with a larger sample size.

As mentioned in the study of Hardy Weinberg equilibrium, it was also revealed that in our study population for intended gene locus in this generation HWE is not seen.This result is expected, because for HWE there must be five conditions: 1) Large population size with random mating, 2) No mutation occurring, 3) No immigration,4) no natural selection, 5) No drift. Our studied population has a small size and there is almost high frequency of kinship marriage in Khuzestan province. Besides it is possible that the mutation, migration and natural selection also affected the population. As the current study is 
a statistical study and the gene locus studied showed no association with T2DM, it is not expected that increasing population size will lead to observing HWE in this case. Although increasing in population size in such studies may change the static analysis and the association results, still evolution forces (mutation, drift, immigration, natural selection and marriage) are active and effecting the gene pool and genotype frequencies.

As implicitly mentioned, a small sample size was one of the limitations of this study. F rom one side, the authorized time for this project was short, and on the other hand, we had some restrictions for selecting individuals. For instance, for more accurate results, the average age of normal individuals should have been more than the average age of patients. The individuals must have been native of Khuzestan prvince, based on project definition. The individuals number of both sexes (male and female) should have been almost equal. The normal individuals must have no family history of T2DM and the age of patients must have not been under 30 years old. So the existence of these restrictions made us unable to accumulate more samples within the time frame defined for the project.

\section{Acknowledgement}

This research was supported financially by the grants from Shahid Chamran University of Ahvaz, Ahvaz, Iran.

\section{References}

1. Nasli-Esfahani E, Farzadfar F, Kouhnavard M, Ghodssi-Ghassemabadi R, Khajavi A, Peimani M, et al. Iran diabetes research roadmap (IDRR) study: a preliminary study on diabetes research in the world and Iran. J Diabetes Metab Disord. 2017 Feb 17;16:9.

2. Latifi SM, Karandish M, Shahbazian H, Hardani Pasand L. Incidence of Prediabetes and Type 2 Diabetes among People Aged over 20 Years in Ahvaz: A 5-Year Perspective Study (2009-2014). J Diabetes Res. 2016; 2016: 4908647.

3. Golozar A, Khalili D, Etemadi A, Poustchi H, Fazeltabar A, Hosseini F, et al. White rice intake and incidence of type-2 diabetes: analysis of two prospective cohort studies from Iran. BMC Public Health. 2017 Jan 31; 17(1): 133.

4. Medina C, Janssen I, Barquera S, Bautista-Arredondo S, González ME, González C. Occupational and leisure time physical inactivity and the risk of type II diabetes and hypertension among Mexican adults: A prospective cohort study. Sci Rep. 2018 Mar 29;8(1):5399.

5. Ashtary-Larky D, Ghanavati M, Lamuchi-Deli N, Payami SA, Alavi-Rad S, Boustaninejad M et al. Rapid Weight Loss vs. Slow Weight Loss: Which is More Effective on Body Composition and Metabolic Risk Factors? Int J Endocrinol Metab. 2017 May 17;15(3):e13249.

6. Hosseini S A, Alipour M, Zakerkish M, Cheraghian B, Ghandil P. The Gene-Treatment Interaction of FTO-rs9939609 Gene Polymorphism and Epigallocatechin-GallateIntervention on Anthropometric Indices, Fasting Blood Sugar and Insulin Resistance/Sensitivity in Patients with Type 2 Diabetes Mellitus. Iran Red Crescent Med J. 2018 ; 20(12):e82228.

7. Kazemi B, Seyed N, Moslemi E, Bandehpour M, Bikhof Torbati M, Saadat N, et al. Insulin receptor gene mutations in Iranian patients with type II diabetes mellitus. Iran Biomed J. 2009 Jul;13(3):161-8.

8. Barra GB, Dutra LA, Watanabe SC, Costa PG, Cruz PS, Azevedo MF, et al. Association of the rs7903146 single nucleotide polymorphism at the Transcription Factor 7-like 2 (TCF7L2) locus with type 2 diabetes in Brazilian subjects. Arq Bras Endocrinol Metabol. 2012 Nov;56(8):47984.

9. Zhang C, Bao W, Rong Y, Yang H, Bowers K, Yeung E, et al. Genetics of type 2 diabetes. World Journal of Diabetes, 2013. 4(4): p. 114.

10. Zhang C, Bao W, Rong Y, Yang H, Bowers K, Yeung $\mathrm{E}$, et al. Genetic variants and the risk of gestational diabetes mellitus: a systematic review. Hum Reprod Update. 2013 Jul-Aug;19(4):376-90.

11. Kang ES, Kim MS, Kim YS, Hur KY, Han SJ, Nam $\mathrm{CM}$, et al. A variant of the transcription factor 7-like 2 (TCF7L2) gene and the risk of posttransplantation diabetes mellitus in renal allograft recipients. Diabetes Care. 2008 Jan;31(1):63-8.

12. Yako YY, Madubedube JH, Kengne AP, Erasmus RT, Pillay TS, Matsha TE. Contribution of ENPP1, TCF7L2, and FTO polymorphisms to type 2 diabetes in mixed ancestry ethnic population of South Africa. Afr Health Sci. 2015 Dec;15(4):1149-60.

13. Peng S, Zhu Y, Lü B, Xu F, Li X, Lai M. TCF7L2 gene polymorphisms and type 2 diabetes risk: a comprehensive and updated meta-analysis involving 121174 subjects. Mutagenesis. 2013 Jan;28(1):25-37.

14. Hou N, Ye B, Li X, Margulies KB, Xu H, Wang X, 
et al. Transcription Factor 7-like 2 Mediates Canonical Wnt/ $\beta$-Catenin Signaling and c-Myc Upregulation in Heart Failure. Circ Heart Fail. 2016 Jun;9(6).

15. Jin T, Liu L. Minireview: the Wnt signaling pathway effector TCF7L2 and type 2 diabetes mellitus. Mol Endocrinol. 2008 Nov;22(11):2383-92.

16. Shao W, Wang D, Chiang YT, Ip W, Zhu L, Xu F, et al. The Wnt signaling pathway effector TCF7L2 controls gut and brain proglucagon gene expression and glucose homeostasis. Diabetes. 2013 Mar;62(3):789-800.

17. Ip W, Chiang YT, Jin T. The involvement of the wnt signaling pathway and TCF7L2 in diabetes mellitus: The current understanding, dispute, and perspective. Cell Biosci. 2012 Aug 14;2(1):28.

18. Vilsbøll T, Holst JJ. Holst, Incretins, insulin secretion and type 2 diabetes mellitus. Diabetologia. 2004 Mar;47(3):357-366.

19. Grant SF, Thorleifsson G, Reynisdottir I, Benediktsson R, Manolescu A, Sainz J, et al. Variant of transcription factor 7-like 2 (TCF7L2) gene confers risk of type 2 diabetes. Nat Genet. 2006 Mar;38(3):320-3. Epub 2006 Jan 15.

20. Renström E. Impact of transcription factor 7-like 2 (TCF7L2) on pancreatic islet function and morphology in mice and men. Diabetologia. 2012 Oct;55(10):2559-2561. 21. Gu X, Zhao F, Zheng M, Fei X, Chen X, Huang S, et al. Cloning and characterization of a gene encoding the human putative ubiquitin conjugating enzyme E2Z (UBE2Z). Mol Biol Rep. 2007 Sep;34(3):183-8.

22. Schunkert H, König IR, Kathiresan S, Reilly MP, Assimes TL, Holm H, et al. Large-scale association analysis identifies 13 new susceptibility loci for coronary artery disease. Nat Genet. 2011 Mar 6;43(4):333-8.
23. Johnson ME, Zhao J, Schug J, Deliard S, Xia Q, Guy $\mathrm{VC}$, et al. Two novel type 2 diabetes loci revealed through integration of TCF7L2 DNA occupancy and SNP association data. BMJ Open Diabetes Res Care. 2014 Dec 1;2(1):e000052.

24. Pourahmadi M, Erfanian S, Moradzadeh M, Jahromi AS. Non-Association between rs7903146 and rs12255372 Polymorphisms in Transcription Factor 7-Like 2 Gene and Type 2 Diabetes Mellitus in Jahrom City, Iran. Diabetes Metab J. 2015 Dec;39(6):512-7.

25. Palizban A, Nikpour M, Salehi R, Maracy MR, Association of a common variant in TCF7L2 gene with type 2 diabetes mellitus in a Persian population. Clin Exp Med. 2012 Jun;12(2):115-9.

26. Khodaeian M, Enayati S, Tabatabaei-Malazy O, Amoli MM. Association between Genetic Variants and Diabetes Mellitus in Iranian Populations: A Systematic Review of Observational Studies. J Diabetes Res. 2015;2015:585917.

27. Alami FM, Samaei NM, Ahmadi M, Tabarraei A, Khosravi A, Tabatabaeifar MA, et al. Association of transcription factor 7-like 2 (Tcf712) gene haplotypes with the risk of type 2 diabetes mellitus in Iran. Advances in Biological Research. 2013;7(5):145-150.

28. Shokouhi S, Delpisheh A, Haghani K, Mahdizadeh M, Bakhtiyari S, et al. Association of rs7903146, rs12255372, and rs290487 polymorphisms in TCF7L2 gene with type 2 diabetes in an Iranian Kurdish ethnic group. Clin Lab. 2014;60(8):1269-76.

29. Amoli MM, Amiri P, Tavakkoly-Bazzaz J, Charmchi E, Hafeziyeh J, Keramatipour M, et al. Replication of TCF7L2 rs7903146 association with type 2 diabetes in an Iranian population. Genet Mol Biol. 2010 Jul;33(3):449-51. 